\title{
BOTTLENECK ANALYSIS OF A CHEMICAL PLANT USING DISCRETE EVENT SIMULATION
}

\author{
Bikram Sharda and Scott J. Bury \\ Process Optimization-Engineering Sciences, Core R\&D \\ The Dow Chemical Company \\ Freeport, TX, USA 77541
}

\begin{abstract}
This paper describes a debottlenecking study for different products in a chemical plant of The Dow Chemical Company. We used discrete event simulation to represent the chemical plant operations and to identify individual processes that limit the plant production. Our analysis successfully identified different bottlenecks for each product. The simulation will be used in future evaluations of the costs and benefits of different solutions identified for validated root causes. The simulation captures plant dynamics and can be easily leveraged to other improvement opportunities in the plant with no to little customization. In this paper, we present the general approach used for identifying the bottlenecks and the analysis results.
\end{abstract}

\section{INTRODUCTION}

Chemical plant operations have complex system interactions and product flows. The operational complexity is compounded by discrete and continuous product flows at different production steps. The production managers continually seek ways to improve production capabilities and to reduce operational costs. Such improvements become more critical when plant production can not meet market demand.

One commonly used approach to improve plant production involves bottleneck analysis. The bottleneck analysis process identifies individual processes in a plant that are contributing towards reduced production rates (Hopp and Spearman 2000). Such analysis falls into the "Analyze" step of a traditional DMAIC (Define, Measure, Analyze, Improve and Control) Six Sigma process (Breyfoggle 1999). Once the bottlenecks are identified, a root cause analysis can then be carried out, which leads to identification of the possible causes. Once the causes are validated, improvement projects can then be carried out to reduce/eliminate the causes.

The presence of numerous system interactions, discrete and continuous product flow, and variability associated with different processing steps, makes a simple analytical approach to bottleneck analysis difficult for chemical plants. Discrete event simulation (DES) is a well suited approach for such analysis, as it captures such complexities with relative ease. The work presented in this paper builds on the simulation expertise developed from other successfully applied DES projects in multiple domains including: improving the capacity of marine terminal operations (Karuppiah, Akiya and Sharda 2009; Bury and Akiya 2005), evaluating capacity and expansion opportunities at tank farm operations (Sharda and Vazquez 2009), and reliability modeling of a chemical plant (Sharda and Bury 2008). The continuity of a simulation group allows it to build on previous experience and this increases the efficiency and productivity of the model building, and directly improves the company's return on their investment in simulation resources. Jahangirian et al. (2009) present a review of simulation applications in manufacturing and business.

This paper describes a debottlenecking study for a chemical plant of The Dow Chemical Company. With changing business dynamics (addition/removal of products, changing product demand), it was important to identify bottlenecks in order to improve the production capability of the plant. The plant pro- 


\section{Sharda and Bury}

duced multiple products, which were either semi-finished or finished products. For the semi-finished products requiring subsequent processing, a bottleneck at this plant lead to reduced production capabilities of downstream plants.

To facilitate the analysis, we developed a DES model to capture the plant dynamics and to incorporate the observed variability associated with individual processes. After successfully validating the model against historical data, we used the model to identify the bottlenecks associated with the production of different products. A team of subject matter experts representing process and engineering knowledge domains then validated these bottlenecks. The identified bottlenecks are now subject to root cause analysis, which in turn will generate the improvement projects to eliminate the bottlenecks.

The DES model will be used in the future to evaluate the costs and benefits of improvements opportunities identified in the root cause analysis. In addition, the model will be leveraged to other improvement projects such as addition of automated transfer lines, and reliability analysis of the plant. For a discussion of a such a reliability study see Sharda and Bury (2008).

This paper is organized as follows. Section 2 describes the chemical plant operations. Section 3 provides a description of the simulation model. Section 4 describes some representative results of the study and finally Section 5 provides the summary and future work.

\section{PROCESS OVERVIEW}

Error! Reference source not found. shows a high level overview of the chemical plant operations with notations on whether a given process is a batch or a continuous operation. Although presented as a sequential operation, there are parallel and converging paths for the material flow. The first step in the operation is preparing the required type of raw material for Process 2. A batch of raw material is processed using equipment in Process 1 and transferred to a storage tank in Storage 1. There are $\mathrm{N}_{1}$ numbers of equipment for Process 1 that operate in parallel and $\mathrm{N}_{2}$ number of storage tanks. At any given time, a batch of raw material can be transferred to only one of the storage tanks (in Storage 1). The storage tanks in Storage 1 can hold one batch.
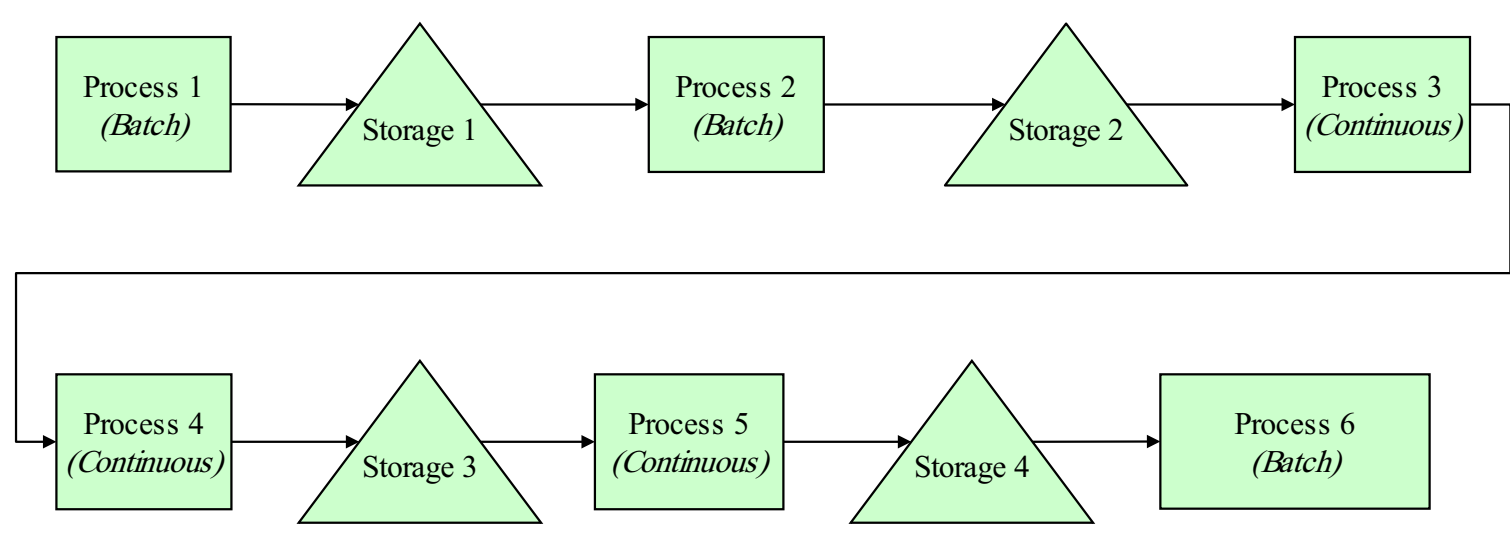

Figure 1. Overview of the plant operations. Each step contains multiple equipment in parallel.

There are $\mathrm{N}_{3}$ numbers of equipment available for carrying out Process 2. Once the equipment is available, a batch of raw material from a storage tank in Storage 1 is transferred. At the end of the process, the completed batch is transferred to a storage tank (Storage 2). The storage tank (Storage 2) can hold 1 batch at a given time. The operations of different equipment for carrying out Process 2 are staged in order to streamline production. Staging implies that the parallel equipment do not start and finish their operations at the same time. This ensures that the equipment are transferring the completed batch to Storage 2 at equal intervals of time, and are not simultaneously waiting for Storage 2 to be empty or storage tanks (in Storage 1) to be filled. Operational constraints limit multiple pieces of equipment simultaneously transferring the completed batch to Storage 2 at the same time. 


\section{Sharda and Bury}

The product stored in Storage 2 is further processed using Process 3 and Process 4 . Process 3 and 4 are integrated processes, and operate at the same production rate. At the end of these processes, the product is transferred to $\mathrm{N}_{4}$ storage tanks in Storage 3. The product stored in Storage 3 is further processed (using Process 5 equipment) and then stored in $\mathrm{N}_{5}$ storage tanks in Storage 4. There are $\mathrm{N}_{5}$ numbers of parallel pieces of equipment in Process 5. The equipment receive product from specific tanks in Storage 3 and transfer product to specific tanks in Storage 4. The parallel equipment can be operated independently of each other.

Each storage tank in Storage 4 can hold products belonging to a specific family. The last step in the production process involves Process 6 . There are $\mathrm{N}_{6}$ pieces of equipment that operate in parallel. The operations of these equipment are also staged in order to streamline production.

\section{SIMULATION MODEL DESCRIPTION}

Figure 2 shows a snapshot of the simulation model developed using ExtendSim ${ }^{\circledR}$ (Diamond et al. 2010). We have found that the hierarchical modeling in ExtendSim ${ }^{\circledR}$ promotes clean and organized model structure that enhances model understanding. In addition, the hierarchical blocks can be easily used in other simulation models that have similar operations. The input data required for running the simulation was stored in the integrated databases in ExtendSim ${ }^{\circledR}$ to facilitate the model parameter changes. The database also simplifies the end-user interactions with the model. The plant data was readily available from the plant database servers. We used JMP ${ }^{\circledR}$ statistical software (SAS Institute 2008) to analyze the data and ExpertFit ${ }^{\circledR}$ distribution fitting software (Law 2006) to generate the distributions for different processing times and flow rates.

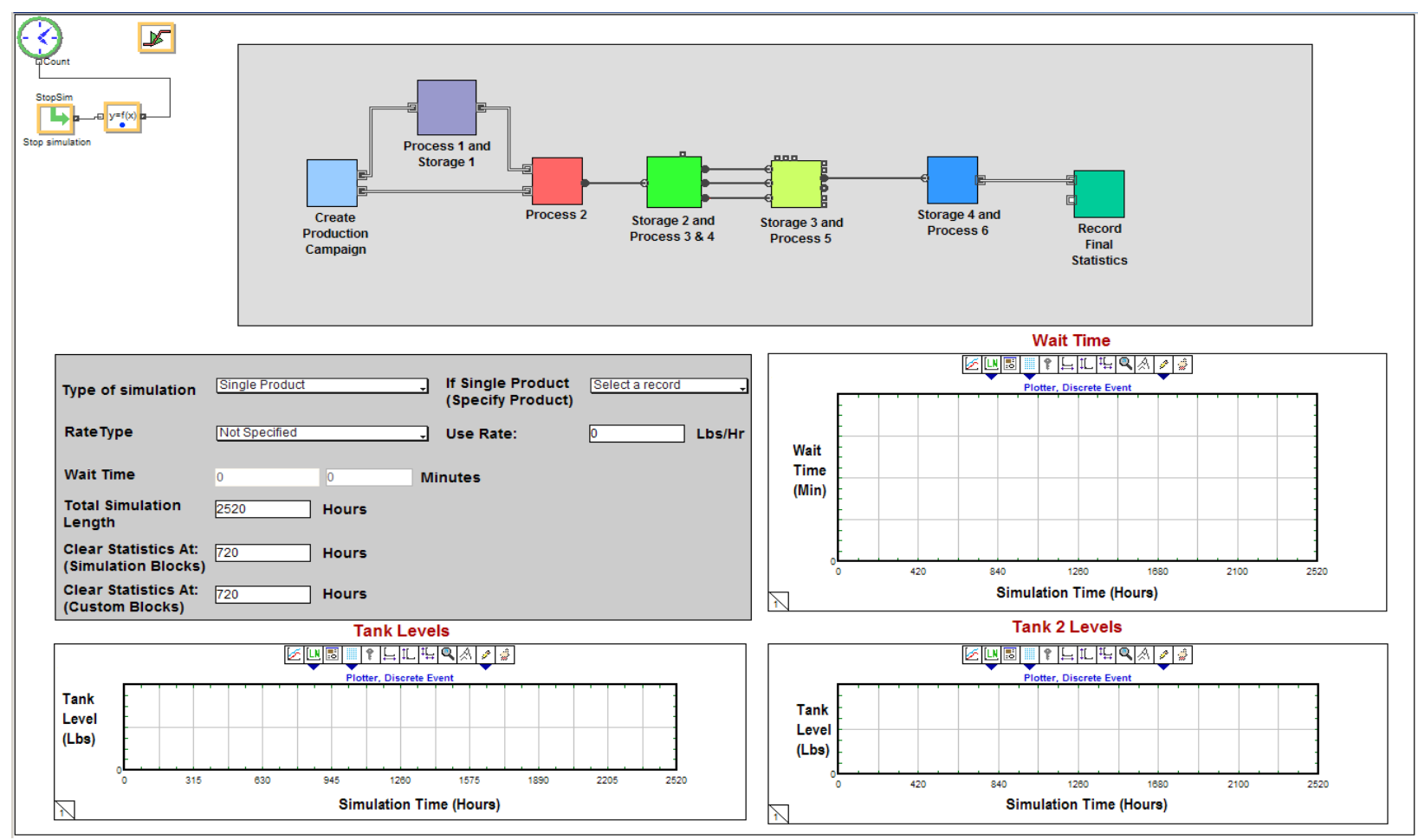

Figure 2. Snapshot of the simulation model

The following databases were created in the simulation model:

- Input parameter database: This database includes data required for running the simulation. This data includes: processing step times (for batch operations), processing rates (for continuous operations) and storage tank capacities. 


\section{Sharda and Bury}

- Run time database: This database includes dynamic variables that are required for executing the simulation logic. During the simulation, the model changes the values of these variables in order to execute the simulation logic. Some example of such variables include: equipment's current step and status, storage tank product and current tank level.

- Simulation output database: The simulation model stores the final simulation statistics in this database. Table 1 lists some of the statistics generated by the simulation model. These statistics were used to validate the simulation model output and to identify the bottlenecks. In addition, these statistics provided differences between design rates and observed production rates of different steps.

Table 1. Simulation statistics used in the model

\begin{tabular}{|l|l|}
\hline Statistic Name & Description \\
\hline Process $1,2,3,4,5$ and 6 rate $(\mathrm{lbs} / \mathrm{hr}$ ) & Average total production rate of the individual processes. \\
\hline $\begin{array}{l}\text { Average delay due to equipment stag- } \\
\text { ing in Process 2 (minutes) }\end{array}$ & $\begin{array}{l}\text { Average amount of time the Process 2 equipment are waiting } \\
\text { due to staging. }\end{array}$ \\
\hline $\begin{array}{l}\text { Average delay due to Process 1 (mi- } \\
\text { nutes) }\end{array}$ & $\begin{array}{l}\text { Average amount of time the equipment for Process } 2 \text { are } \\
\text { waiting for the raw product to be loaded in Storage } 1 \text { tanks. }\end{array}$ \\
\hline $\begin{array}{l}\text { Total average delay time of Process } 2 \\
\text { equipment due to Process } 1 \text { and Process } \\
2 \text { equipment staging (minutes) }\end{array}$ & $\begin{array}{l}\text { Average total amount of time an equipment in Process } 2 \\
\text { waits due to staging and raw product loading in Storage } 1 \\
\text { tanks. }\end{array}$ \\
\hline $\begin{array}{l}\text { Average wait time of Process 2 equip- } \\
\text { ment for Storage 2 emptying (minutes) }\end{array}$ & $\begin{array}{l}\text { Average amount of time the Process 2 equipment are waiting } \\
\text { for Storage 2 tank to be empty. }\end{array}$ \\
\hline Average batches/day & $\begin{array}{l}\text { Average daily number of production batches produced from } \\
\text { Process 2. }\end{array}$ \\
\hline $\begin{array}{l}\text { Average batch transfer time to Process } \\
6 \text { equipment (minutes) }\end{array}$ & $\begin{array}{l}\text { Average amount of time to transfer one product batch from } \\
\text { Storage 4 to equipment in Process } 6 .\end{array}$ \\
\hline $\begin{array}{l}\text { Average cycle time for Process } 6 \text { (mi- } \\
\text { nutes) }\end{array}$ & $\begin{array}{l}\text { Average amount of time taken to complete } 1 \text { batch in equip- } \\
\text { ment in Process } 6 .\end{array}$ \\
\hline
\end{tabular}

The first phase of the model development involved getting a clear understanding of plant operations and developing the entire process logic on paper. We use the Six Sigma "Define" process (Breyfoggle 1999) to ensure problem definition, scope, boundaries and key deliverables are clearly documented and understood by the project stakeholders and the modelers. Development of model logic on "paper" helps to insure that the logic implemented can be easily understood by people not directly involved in the model programming. Different metrics that need to be computed during the simulation model and data requirement for the model are identified, and owners responsible to gather this data are assigned (Sharda and Vazquez, 2009).

After developing the model, the simulation model was verified and key model constraints were checked. This involved checking different aspects such as: equipment staging (Process 2 and Process 6), sequencing of transfers and the correct storage of product in correct tanks.

After successfully verifying the simulation model, the output of the simulation was validated against the historical data. We used the following simulation model settings for our analysis:

- Number of simulation runs: 10

- Total simulation length: 6 months, excluding warm up period

- Warm up period: 1 month

These simulation settings showed good model convergence and a steady state behavior. Interested readers can refer to Law and Kelton (2000) and Banks et al. (2005) for more information on finding appropriate simulation model settings.

During the simulation model validation, we performed a statistical analysis to compare the output of the simulation model against historical data. A team of cross functional experts were involved in the validation phase. Different metrics that were validated included processing times for different steps (such as 


\section{Sharda and Bury}

equipment cycle time and processing rates). In addition, we evaluated the daily production rate (lbs/day) for each product against historical production rates of each product. Our analysis found that the simulation model output results were statistically (and practically) indistinguishable from the historical data.

\section{RESULTS}

After successful validation, the simulation model was used to identify the bottlenecks for each product. Table 2 shows a sample summary report showing the $1^{\text {st }}$, and $2^{\text {nd }}$ level bottlenecks for each product, generating a chain of bottlenecks that can be addressed in sequence to achieve the production improvements. Table 3 shows the production comparison by removing $1^{\text {st }}$ level bottleneck. The numbers listed in the table have been arbitrarily scaled for confidentiality. The level of bottleneck indicate the order in which each bottleneck source should be eliminated in order to improve production. For example, for Product B, the production is limited due to lower production rates in Processes $3 \& 4$ ( $1^{\text {st }}$ level bottleneck). If the issues in Process 3 and Process 4 are completely eliminated, then the next bottleneck source limiting the plant production will be Process $2\left(2^{\text {nd }}\right.$ level). In order to find the $2^{\text {nd }}$ level bottleneck, the throughput rates of $1^{\text {st }}$ level bottleneck are artificially eliminated, which exposes the next limiting step. Table 3 shows the production comparison by removing $1^{\text {st }}$ level bottleneck.

Table 2. Sample report showing bottleneck levels for different products

\begin{tabular}{|c|c|c|c|c|c|}
\hline $\begin{array}{c}\text { Product } \\
\text { Name }\end{array}$ & Process 1 & Process 2 & $\begin{array}{c}\text { Process 3 and } \\
\text { Process 4 }\end{array}$ & Process 5 & Process 6 \\
\hline A & 1 & & 2 & & \\
\hline B & & 2 & 1 & & 1 \\
\hline C & & & 2 & & 1 \\
\hline
\end{tabular}

Table 3. Sample report showing production improvements with $1^{\text {st }}$ level bottleneck removal

\begin{tabular}{|l|l|l|l|}
\hline $\begin{array}{l}\text { Product } \\
\text { Name }\end{array}$ & $\begin{array}{c}\text { Production rate us- } \\
\text { ing simulation } \\
\text { (batches/day) }\end{array}$ & $\begin{array}{c}\text { Production rate using simula- } \\
\text { tion by removing } \mathbf{1}^{\text {st }} \text { level bot- } \\
\text { tleneck (batches/day) }\end{array}$ & $\begin{array}{c}\text { Percentage improve- } \\
\text { ment in average pro- } \\
\text { duction rate }\end{array}$ \\
\hline $\mathrm{A}$ & $10 \pm 0.11$ & $11 \pm 0.1$ & $10 \%$ \\
\hline $\mathrm{B}$ & $8 \pm 0.1$ & $9 \pm 0.1$ & $13 \%$ \\
\hline $\mathrm{C}$ & $7 \pm 0.1$ & $8 \pm 0.1$ & $14 \%$ \\
\hline
\end{tabular}

We used the simulation statistics (see Table 1) and integrated visual plots (see Figure 2) to identify different bottlenecks for each product. Table 4 shows the possible causes or identifying statistic for different bottleneck sources. The simulation based analysis provided systematic investigation to identify bottleneck chains and validated previously hypothesized bottlenecks.

An example of the bottleneck analysis is illustrated for Product C. For Product C, Process 6 rates were identified as a bottleneck source. Figures 3, 4 and 5 show the average product level in Storage 3, average product level in Storage 4, and Process 2 equipment wait time for Storage 2 emptying respectively. The vertical axis in the figures has been intentionally omitted due to confidentiality.

For this product, we notice that Storage 3 (Figure 3) and Storage 4 (Figure 4) tank levels continue to increase during the simulation, and Storage 3 reaches its maximum capacity at $\sim 1680$ hours. At this time, the Process 2 equipment wait time starts to increase. Increase in Storage 4 levels can only be attributed to slower production rate of Process 6 equipment. Statistics on batch transfer time to Process 6 equipment verified that the Process 6 equipment were not starving for the Product $\mathrm{C}$ from Storage 4. These findings confirmed that the Process 6 equipment were the $1^{\text {st }}$ level bottleneck for this product. 


\section{Sharda and Bury}

Table 4. Bottlenecks and leading indicators or causes

\begin{tabular}{|c|c|}
\hline Bottleneck Source & Possible Indicators \\
\hline Process 1 & - $\quad$ Average Process 2 delay due to Process 1 (minutes) \\
\hline Process 2 & $\begin{array}{ll}\text { - } & \text { Average Process } 2 \text { delay due to Process } 1 \text { (minutes) } \\
\text { - } & \text { Average delay due to equipment staging in Process } 2 \text { (minutes) } \\
\text { - } & \text { Average wait time of Process } 2 \text { equipment for Storage } 2 \text { emptying } \\
\text { (minutes) } \\
\text { - }\end{array}$ \\
\hline Process $3 \& 4$ & $\begin{array}{l}\text { - } \begin{array}{l}\text { Average wait time of Process } 2 \text { equipment for Storage } 2 \text { emptying } \\
\text { (minutes) }\end{array} \\
\text { - } \quad \text { Average batch transfer time to Process } 6 \text { equipment (minutes) } \\
\text { - Comparison of Process } 3 \& 4 \text { production rate against Process 1, 2, } \\
5 \text { and } 6 .\end{array}$ \\
\hline Process 5 & $\begin{array}{l}\text { - Comparison of Process } 5 \text { production rate against Process } 1,2,3,4 \\
\text { and } 6 . \\
\text { - Average wait time of Process } 2 \text { equipment for Storage } 2 \text { emptying } \\
\text { (minutes) } \\
\text { - Average batch transfer time to Process } 6 \text { equipment (minutes) }\end{array}$ \\
\hline Process 6 & $\begin{array}{l}\text { - Comparison of Process } 6 \text { production rate against Process } 1,2,3,4 \\
\text { and } 5 . \\
\text { - Average wait time of Process } 2 \text { equipment for Storage } 2 \text { emptying } \\
\text { (minutes) } \\
\text { - Average batch transfer time to Process } 6 \text { equipment (minutes) }\end{array}$ \\
\hline
\end{tabular}

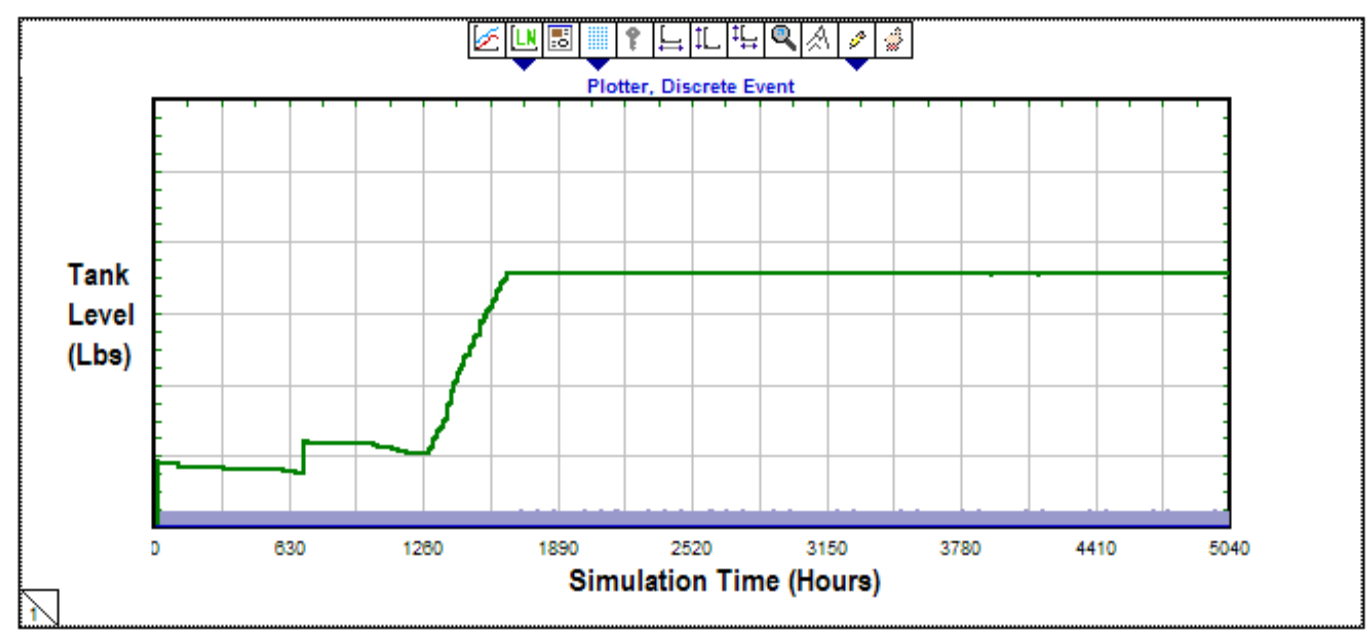

Figure 3. Average Product C level in Storage 3 


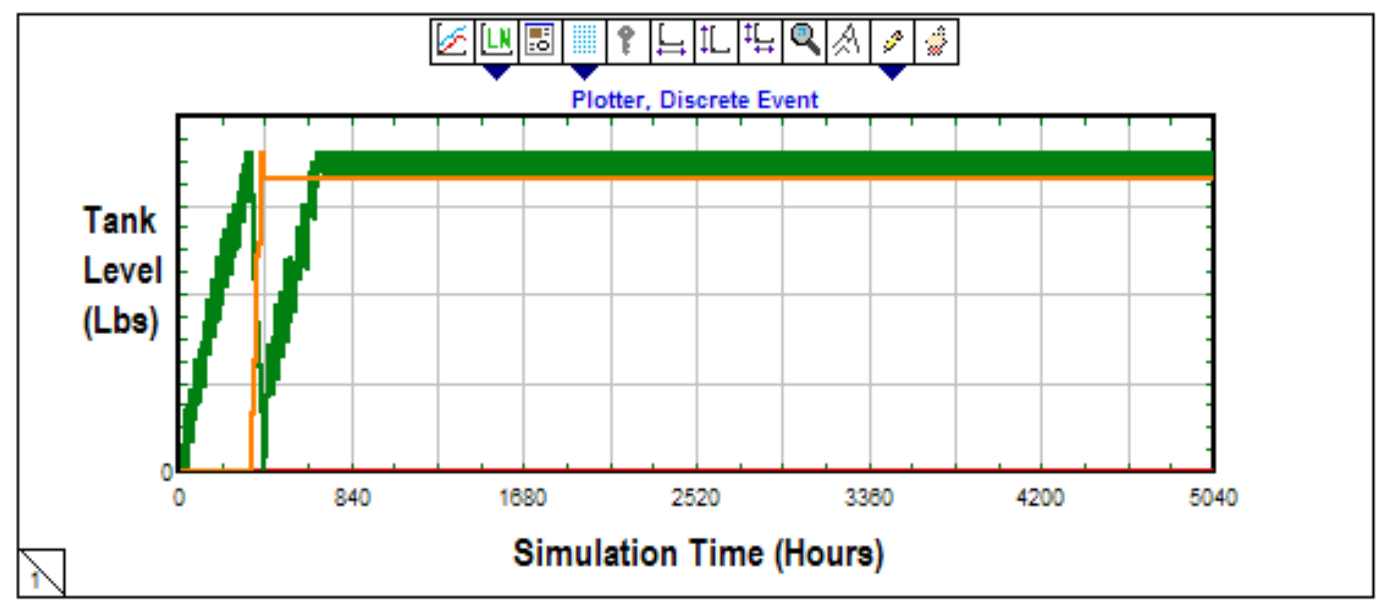

Figure 4. Average Product C level in Storage 4

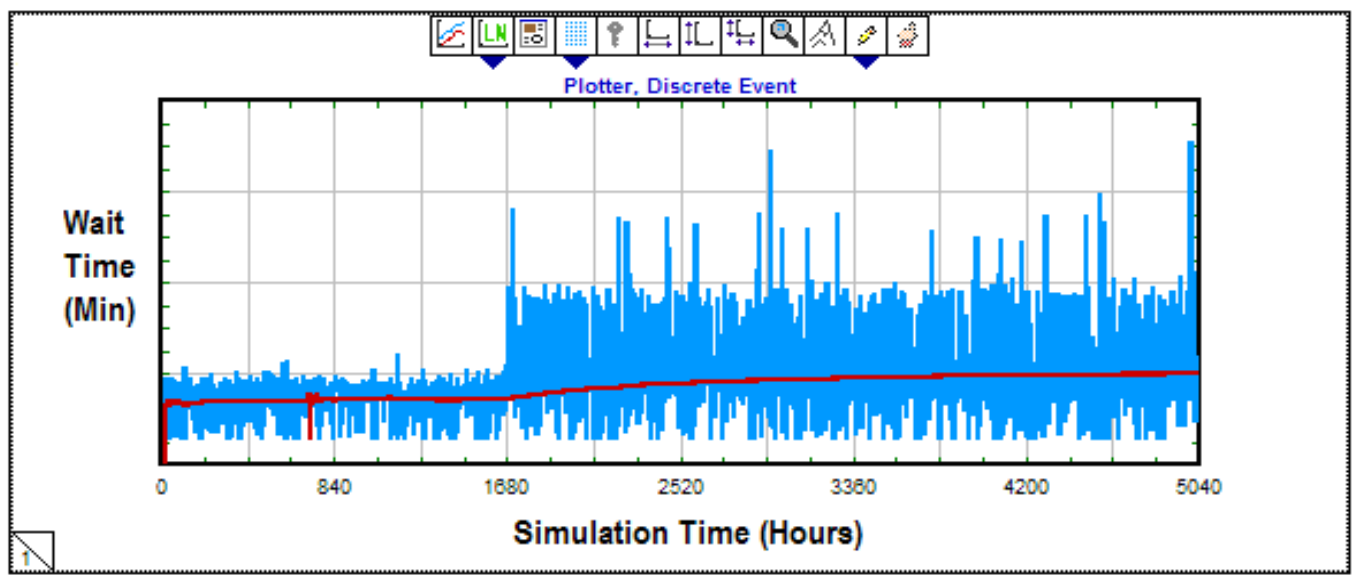

Figure 5. Average Process 2 equipment wait time for Storage Tank 2 emptying for Product $\mathrm{C}$

To find the $2^{\text {nd }}$ level bottleneck, the Process 6 rates were set to a high value so that they are no longer a bottleneck. We notice that the statistics on wait time of Process 2 equipment for Storage 2 emptying were significantly higher than the "designed" wait times provided by the subject matter experts. Although, these times were less than the times obtained by including $1^{\text {st }}$ level bottlenecks (See

Figure 5 and Figure 6). Storage 3 and Storage 4 tank levels were running at near zero capacity, indicating starving of Process 5 and Process 6. Low tank levels of Storage 3 and 4 implies that Process 3 and Process 4 were a source of bottleneck. To verify this assumption, the Process 3 and Process 4 rates was set to an arbitrarily higher value. With the higher rates, we observed that the Process 2 equipment wait times were equal to the "ideal" wait times. 


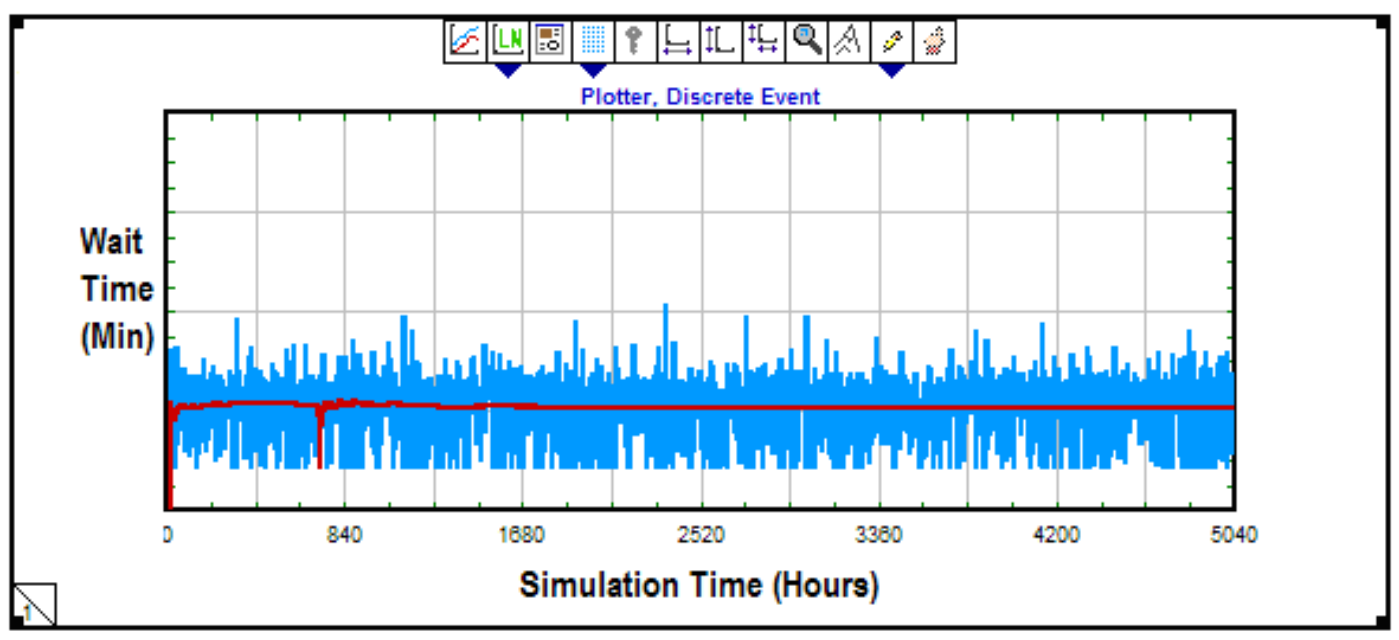

Figure 6. Process 2 equipment wait time after removing $1^{\text {st }}$ level bottleneck

\section{SUMMARY}

This paper describes an application of discrete event simulation to facilitate bottleneck analysis for production of different products in a chemical plant of The Dow Chemical Company. The project team successfully used the simulation model to study the dynamic behavior of the process and used the data generated by the simulation to identify bottleneck chains for different products, which if eliminated, can lead to production improvements. Currently we are in the process of identifying possible root causes behind the bottlenecks. The model will be used in future to evaluate the costs and benefits of the identified solutions. The simulation model constitutes a general framework that captures key plant operations and will be leveraged for other improvement projects within the plant. Another extension of this work involves reliability analysis of the plant, which is similar to our earlier work (see Sharda and Bury 2008).

\section{ACKNOWLEDGMENTS}

We would like to thank the business for their support of new modeling approaches and express our appreciation of the team members for providing their expertise at different phases of the project. In addition, we would like to thank ExtendSim ${ }^{\mathbb{B}}$ support team especially Cecile Damiron, Anthony Nastasi and Dave Krahl for providing timely and valuable support during the model development.

\section{AUTHOR BIOGRAPHIES}

BIKRAM SHARDA is a Senior Engineer in Process Optimization group of The Dow Chemical Company's Engineering Sciences organization within Core R\&D. His research interests include simulation and mathematical modeling, risk analysis, Bayesian statistics, data mining and pattern recognition. He is a member of INFORMS and a certified Green Belt Project Leader. His email address is <brsharda@dow. com>.

SCOTT J. BURY is a Principal Research Scientist in the Process Optimization group of The Dow Chemical Company's Engineering Sciences organization within Core R\&D. His research interests include process simulation \& optimization of chemical processes using both continuous and discrete event technology and eliminating failure modes when implementing new process technology. He is a certified Six Sigma Black Belt. He is a member of INFORMS and ASQ. His email address is < sjburyedow.com $>$. 


\section{Sharda and Bury}

\section{REFERENCES}

Banks J., J.S. Carson, B.L. Nelson, and D.M. Nicol. 2005. Discrete event system simulation. $4^{\text {th }}$ ed. Prentice Hall International series in Industrial and Systems.

Breyfoggle III, F.W.. 1999. Implementing Six Sigma: Smarter Solutions Using Statistical Methods. New York: John Wiley \& Sons.

Bury, S.J., and A. Naoko. 2005. Evaluating proposed capital and operational improvements at a marine terminal. In Proceedings of the 2005 Winter Simulation Conference. ed. M. E. Kuhl, N. M. Steiger, F. B. Armstrong, and J. A. Joines, 2005-2010. Piscataway, New Jersey: Institute of Electrical and Electronics Engineers.

Diamond, B., P. Diamond, S. Lamperti, D. Krahl, C. Sackett, A. Nastasi, C. Damiron, P. Tag and K. Hansen. 2010. ExtendSim User Guide V8. Imagine That Inc.. <http://www.extendsim.com> [accessed August 14, 2010].

Hopp, W., and M. Spearman 2000. Factory Physics, McGraw-Hill/Irwin.

Karuppiah, R., N. Akiya, and B. Sharda. 2009. On improving the capacity of marine terminal operations using discrete event simulation. Poster presentation in Proceedings of 2009 Winter Simulation Conference, ed. M.D. Rossetti, R.R. Hill, A. Johansson, A. Dunkin, and R.G. Ingalls. Piscataway, New Jersey: Institute of Electrical and Electronics Engineers.

Law, A.M., and W.D. Kelton. 2000. Simulation modeling and analysis. $3^{\text {rd }}$ ed. New York: McGraw-Hill.

Law, A.M. 2006. ExpertFit ${ }^{\circledR}$ Distribution-Fitting Software. <http://www.averill-law.com> [accessed August 14, 2010].

SAS Institute Inc. 2009. JMP ${ }^{\circledR}<$ http: / / www . jmp. com $>$ [accessed August 14, 2010].

Sharda, B. and S.J. Bury. 2008. A discrete event simulation model for reliability modeling of a chemical plant. In Proceedings of 2008 Winter Simulation Conference, ed. S.J. Mason, R.R. Hill, L. Mönch, O. Rose, T. Jefferson, and J.W. Fowler, 1736-1740. Piscataway, New Jersey: Institute of Electrical and Electronics Engineers.

Sharda, B. and A. Vazquez. 2009. Evaluating capacity and expansion opportunities at a tank farm: a decision support system using discrete event simulation. In Proceedings of 2009 Winter Simulation Conference, ed. M.D. Rossetti, R.R. Hill, A. Johansson, A. Dunkin, and R.G. Ingalls. 2218-2224. Piscataway, New Jersey: Institute of Electrical and Electronics Engineers.

Jahangirian, M., T. Eldabi, A. Naseer, L.K. Stergioulas, and T. Young, 2009. Simulation in manufacturing and business: A review. European Journal of Operational Research 203(1):1-13. 